\title{
Skull base chordomas: clinical outcome in a consecutive series of 45 patients with long-term follow-up and evaluation of clinical and biological prognostic factors
}

\author{
Nicola Boari, MD, ${ }^{1}$ Filippo Gagliardi, MD, ${ }^{1}$ Andrea Cavalli, MD, ${ }^{2}$ Marco Gemma, MD, ${ }^{3}$ \\ Luca Ferrari, PhD, ${ }^{4}$ Paola Riva, PhD, ${ }^{4}$ and Pietro Mortini, MD ${ }^{1,2}$ \\ ${ }^{1}$ Unit of Neurosurgery and Gamma Knife Radiosurgery; ${ }^{3}$ Service of Anesthesia and Intensive Care Unit, Head and Neck \\ Department, I.R.C.C.S. San Raffaele Hospital; ${ }^{2}$ Vita-Salute San Raffaele University; and ${ }^{4}$ Department of Medical Biotechnology \\ and Translational Medicine, University of Milan, Italy
}

OBJECTIVE Skull base chordomas (SBCs) are rare dysembryogenetic invasive tumors with a variable tendency for recurrence. According to previous studies, the recurrence rate seems to be affected by both clinical variables and tumor biological features. The authors present the results of treatment of SBCs in a large series of patients and investigate the role of 1p36 chromosomal region loss of heterozygosity $(\mathrm{LOH})$ as a prognostic factor.

METHODS Between 1990 and 2011, 45 patients were treated for SBCs. The mean follow-up was 76 months (range 1-240 months). An LOH analysis was performed in 27 cases. Survival analysis was performed to determine clinical and biological parameters correlating with clinical outcome.

RESULTS The 5- and 10 -year overall survival rates were $67 \%$ and $57 \%$, respectively. Five- and 10 -year progressionfree survival rates were $58 \%$ and $44 \%$, respectively. Multivariate analysis showed that extent of resection, adjuvant radiation therapy, and absence of rhinopharynx invasion were positive independent predictors of overall survival. The latter 2 variables and a younger patient age were positive independent predictors of progression-free survival. Twenty-one patients showed $1 \mathrm{p} 36 \mathrm{LOH}$. All events of recurrence and death clustered in the group of patients with $1 \mathrm{p} 36 \mathrm{LOH}$; however, this biological marker was not statistically significant on multivariate analysis.

CONCLUSIONS Resection is the treatment of choice in primary and recurrent SBC. Patient age, rhinopharynx invasion at diagnosis, extent of tumor removal, and postoperative radiation therapy influence SBC prognosis. Genetic analysis, even while showing interesting results, did not reveal 1 p36 LOH as an independent predictor of clinical outcome.

http://thejns.org/doi/abs/10.3171/2015.6.JNS142370

KEY WORDS chordoma; clivus; skull base surgery; radiation therapy; loss of heterozygosity

$\mathrm{C}$ HORDOMAS are rare, mainly extradural, midline primary bone tumors arising from notochord remnants. ${ }^{11,56}$ Although extremely rare, primary intradural chordomas have been reported as well. ${ }^{17,18,36,57,58}$ The most common locations for these lesions are the sacrococcygeal region (55\% of cases), spheno-occipital area (35\%), and vertebral column (10\%).., 20 They have an incidence of 1 case in 2 million persons per year and a prevalence of 1.21 cases in 10 million of the population, accounting for only $0.1 \%-0.2 \%$ of all cranial base tumors. ${ }^{49}$

They are encapsulated tumors that infiltrate bone along the lines of least resistance. ${ }^{10}$ Their growth pattern is characterized by bone infiltration, dural penetration, en- casement of neurovascular structures, and possible brainstem adhesions, which makes chordomas challenging to treat. ${ }^{49,50}$ Prognosis is poor ${ }^{15}$ and is impacted by patient age at the onset of symptoms, extent of resection, and pathological patterns. ${ }^{10}$ The mean survival of untreated patients ranges between 6 and 24 months. ${ }^{24}$ In treated patients the reported 5-year survival rate ranges from $50 \%$ to $85 \%{ }^{8,10}$ Extensive resection followed by high-dose radiotherapy provides the best chance of obtaining long-term tumor control. ${ }^{1,3,6,22,25,49,53}$ Previous studies have highlighted recurrence rates that seem to be affected not only by clinical variables such as tumor extension, extent of resection, and postoperative radiation therapy, but also by tumor

ABBREVIATIONS CCJ = craniocervical junction; GKRS = Gamma Knife radiosurgery; KPS = Karnofsky Performance Scale; LOH = loss of heterozygosity; OS = overall survival; PFS = progression-free survival; $\mathrm{SBC}=$ skull base chordoma.

SUBMITTED October 15, 2014. ACCEPTED June 30, 2015.

INCLUDE WHEN CITING Published online January 8, 2016; DOI: 10.3171/2015.6.JNS142370. 
biological features. ${ }^{32-35,41,42,44,48}$ Common genetic lesions in chordoma are $1 \mathrm{p} 36,3 \mathrm{p}$, and $12 \mathrm{p}$ losses and 1q, 7q, and $9 \mathrm{q}$ gains. ${ }^{26} \mathrm{~A}$ loss of heterozygosity $(\mathrm{LOH})$ study centered on the $1 \mathrm{p} 36$ region revealed an interestingly high incidence of 1p36 losses among sporadic chordomas. ${ }^{27,29,48}$ Failure of apoptosis is known to be a key mechanism for the induction and maintenance of the neoplastic phenotype and is believed to be involved in notochord regression. ${ }^{27}$ The presence of several genes mapped to $1 \mathrm{p} 36$ and involved in the apoptotic pathways prompted us to perform $\mathrm{LOH}$ analysis in our chordoma samples to investigate a possible correlation between this molecular marker and clinical outcome.

We present the results of treatment of skull base chordomas (SBCs) in a large series of patients treated at a single center during a 21-year period. The results of univariate and multivariate statistical analyses performed to define possible correlations between clinical and biological variables and survival are reported.

\section{Methods \\ Patient Population}

Between 1990 and 2011, 45 consecutive patients harboring SBCs were managed at our institution. All patients gave informed consent for the clinical treatments and genetic analysis. Ethics committee approval was not requested because this was a retrospective study derived from the review of a prospectively collected database; the results of genetic analysis did not impact treatment strategy.

\section{Preoperative and Postoperative Evaluation}

On hospital admission all patients underwent neurological examination and radiological assessment involving MRI, CT, MR or CT angiography, and digital subtraction angiography in selected cases. Patient functional status was evaluated using the Karnofsky Performance Scale (KPS).

Follow-up MR images, neurological examination, and ophthalmological and audiometric evaluation when needed were scheduled 3 months after surgery, at 6-month intervals for the first 5 years after surgery, and annually thereafter in survivors. Operative death was defined as death within 28 days following a surgical procedure. To evaluate how treatments impacted patient quality of life we compared pre- and postoperative KPS scores, considering the best score assessed at the clinical follow-up.

\section{Tumor Location and Extent of Resection}

Tumor location was defined according to the Sekhar classification. ${ }^{18}$ Rhinopharynx invasion was assessed at preoperative MRI and was defined as tumor involvement of the rhinopharynx posterior and/or lateral walls (Fig. 1). Posterior wall structures are represented by pharyngobasilar fascia, constrictor pharyngeal muscles, and prevertebral fascia and muscles (longus capitis and longus colli); lateral wall structures are represented by Eustachian tubes, salpingopharyngeal folds, and Rosenmüller's fossae. The MRI findings were confirmed intraoperatively by direct assessment of the invasion of the aforementioned anatomical structures.
Location and extension of the lesions are summarized in Table 1. In 21 cases (47\%) the tumor was completely extradural, while in 24 cases $(53 \%)$ the tumors invaded the intradural space. Extent of resection was determined on the MR images obtained 3 months after surgery and was classified as gross total (no residual tumor or a small questionable area), subtotal (more than $90 \%$ of mass resected), partial (between 50\% and 90\% of mass resected), and biopsy (removal of anything less than $50 \%$ of tumor).

\section{Pathological Diagnosis and LOH Analysis}

Pathological diagnosis was accomplished in accordance with criteria described by Holton and colleagues. ${ }^{21,44}$ The $\mathrm{LOH}$ analysis was performed on available histological specimens from 27 patients using 33 microsatellite markers included in the 1p36.33-1p36.12 genomic interval, 5 microsatellites (D1S2841, D1S1172, D1S2868, D1S2726, and D1S2696) mapped at 1p, and 6 microsatellites (D1S498, D1S400, D1S238, D1S413, D1S1175, and D1S2800) mapped at 1q, according to the University of California Santa Cruz Database (http://www.ucsc.com). Tumor DNA was obtained from 27 fresh or frozen SBCs using Trizol reagent (Life Technologies). Constitutional DNA was obtained from peripheral blood cells by means of QIAamp DNA Blood Mini Kit (Qiagen). The tumor and peripheral blood genomic DNAs were amplified by polymerase chain reaction using a carboxyfluorescein- or hexachlorofluorescein-labeled forward primer for each marker (Sigma Aldrich), and the DNA fragments were separated by means of capillary electrophoresis (ABI 3130XL, Applied Biosystems). To evaluate LOH, the peak areas of both alleles were measured by means of Genemapper software (version 3.1, Applied Biosystems), and the ratios of the blood $(\mathrm{N})$ and tumor $(\mathrm{T})$ samples were compared: a ratio $([\mathrm{T} 2 \times \mathrm{N} 1] /[\mathrm{T} 1 \times \mathrm{N} 2]$ or $[\mathrm{T} 1 \times \mathrm{N} 2] /[\mathrm{T} 2$ $\times$ N1]) of 0.7 is indicative of allele loss, ratios between 0.71 and 0.79 require evaluation of surrounding regions, and ratios of 0.8 are considered to retain heterozygosis as reported in detail by Nishimura et al. ${ }^{37}$

\section{Survival Analysis}

Statistical analyses were performed using Stata software version 11.1 (StataCorp). Survival analysis was performed according to the Kaplan-Meier method. Progression-free survival (PFS) and overall survival (OS) time were calculated from the conclusion of treatment. Overall survival was defined as the time from diagnosis to disease-specific death or the end of observation. Censoring was applied to the last follow-up date if no death occurred or to the death date if death was not disease specific. Death from complications ensuing after surgery occurred in 2 cases and was considered disease specific. The 2 patients who died of non-disease-specific causes 158 and 240 months after treatment, respectively, were included in the analyses. Overall survival analysis was thus performed on the entire population of 45 patients. Progression-free survival was defined as the time from treatment until radiological evidence of tumor regrowth. Progression-free survival analysis was conducted on 43 patients; the 2 patients who died of surgery-related complications were excluded.

Univariate analysis was performed on the Kaplan-Meier curves. Prognostic factors with $\mathrm{p}$ values $<0.2$ on uni- 

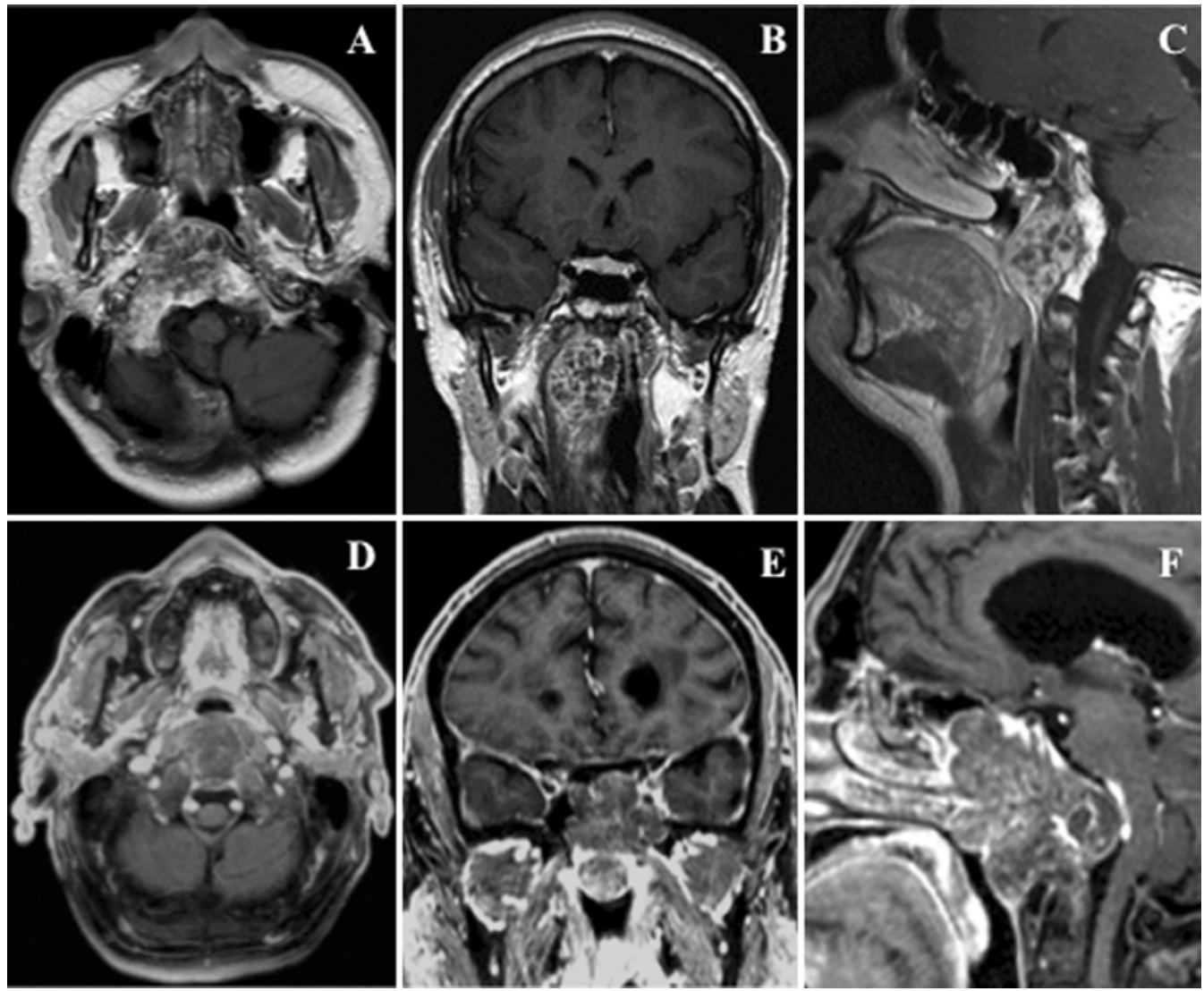

FIG. 1. Preoperative axial, coronal, and sagittal MRI sequences of 2 representative cases of rhinopharynx invasion. In the first case $(\mathbf{A}-\mathbf{C})$, clear invasion of the posterior and right lateral walls of the rhinopharynx is noticeable. In the second case (D-F), the tumor clearly involves the posterior wall of the rhinopharynx.

variate analysis were subject to multivariate analysis using a Cox proportional-hazards regression model. A p value $<$ 0.05 signified statistical significance. Given the distribution of LOH values (quasi-separation with no deaths and no relapses in patients with negative $\mathrm{LOH}$ ), models possibly involving $\mathrm{LOH}$ were also tested using robust estimation of variance and by applying Firth's penalized maximum likelihood logistic regression. Overall significance of multivalue variables was assessed with the Wald test. In fitting the multivariate model, age was considered continuous. Proportionality of hazards was verified for each variable by visual inspection of log-log plots and with the proportional-hazards assumption test based on Schoenfeld residuals. Interactions between significant variables in the final model were searched. Harrell's concordance (C) index was calculated for each model: a Harrell's $C$ index value of 0.5 indicates no predictive discrimination at all, while perfect prediction of patient outcomes yields a $\mathrm{C}$ index value of 1.0 .

\section{Results}

\section{Patient Population}

Of the 45 patients referred to our department between 1990 and 2011, 30 (67\%) were male and 15 (33\%) were female. The female/male ratio was 1:2. Patient age at the first diagnosis ranged from 4 to 71 years (mean \pm SD, 46.7
TABLE 1. Tumor location and extension

\begin{tabular}{cc}
\hline Location & \\
\hline Upper & $1(2 \%)$ \\
\hline Upper + middle & $16(36 \%)$ \\
\hline Middle & $10(22 \%)$ \\
\hline Middle + lower & $9(20 \%)$ \\
\hline Lower & $1(2 \%)$ \\
\hline Upper + middle + lower & $8(18 \%)$ \\
\hline Extension & $19(42 \%)$ \\
\hline Sphenoid sinus & $16(36 \%)$ \\
\hline Sella & $15(33 \%)$ \\
\hline Cavernous sinus & $14(31 \%)$ \\
\hline Rhinopharynx & $7(15 \%)$ \\
\hline Ethmoid infratemporal fossa & $5(11 \%)$ \\
\hline Suprasellar region & $5(11 \%)$ \\
\hline C-1 & $4(9 \%)$ \\
\hline Nasal cavity & $3(7 \%)$ \\
\hline Occipital condyle & $3(7 \%)$ \\
\hline Orbit & $3(7 \%)$ \\
\hline Maxillary sinus & $3(7 \%)$ \\
\hline &
\end{tabular}


\pm 17.4 years). Eighteen patients $(40 \%)$ had undergone previous treatments: $10(56 \%)$ resection, $8(44 \%)$ biopsy, 3 $(17 \%)$ radiation therapy, and $3(17 \%)$ chemotherapy with tyrosine kinase inhibitors. The median time between the initial operation at another institution and the first operation in our department was 13 months (average 34.3 months, range 2-110 months).

Presenting symptoms were diplopia in 27 cases $(60 \%)$; headache in 13 (28.9\%); palpebral ptosis in 6 (13.3\%); hoarseness/dysphagia and visual loss in 5 (11.1\%); facial numbness/pain in 4 (8.9\%); neck pain in 3 (6.7\%); nasal obstruction, hearing loss, facial palsy, and tetraparesis in 2 (4.4\%); hemiparesis, tongue atrophy, dizziness, dysarthria, and urinary incontinence in $1(2.2 \%)$. At the time of diagnosis 17 patients (38\%) were fully active (KPS Score 100), $27(60 \%)$ were moderately to severely impaired (KPS Score 70-100), and 1 (2\%) was unable to function without assistance (KPS score < 70). The mean KPS score at our first preoperative clinical evaluation was 89.78 (range 60-100).

\section{Surgical Treatment}

Sixty-eight operations were performed by the senior author (P.M.) in the initial or recurrent setting. Staged operations were performed in 10 patients (22\%), in 2 stages in 7 of these cases (70\%) and in 3 stages in 3 of these cases (30\%). Gross-total resection was achieved in 19 patients (42.2\%), subtotal in $18(40 \%)$, and partial in $6(13.3 \%)$. In 2 patients $(4.5 \%)$ a biopsy was performed. Gross-total tumor resection was achieved in 15 patients (43\%) among those who had no prior attempted resection and in 4 patients (40\%) among those who had undergone prior surgical treatment. Thirty-two cases (71\%) were typical chordomas and $13(29 \%)$ were chondroid.

\section{Radiation Therapies}

Thirty-four patients $(75.5 \%)$ received postoperative radiation therapy. From 1990 to 2001 the decision to perform postoperative radiotherapy was considered on a case-bycase basis and was usually performed in instances of incomplete resection. Since 2001 proton beam radiotherapy or conventional high-dose radiotherapy was administered to the tumor bed regardless of the extent of tumor removal. In our series of 45 patients, 11 did not undergo any adjuvant radiation therapy: 2 because of severe postoperative complications, 3 because gross-total resection was performed before 2001 and postoperative radiation therapy was decided against, 2 because they were not eligible due to a very young age, 3 because they had already undergone radiation therapy as previous treatment, and 1 because the patient refused the treatment. The radiation delivery method included proton beam radiotherapy in $19(56 \%)$ cases, fractionated radiotherapy in 7 (20.6\%), and Gamma Knife radiosurgery (GKRS) in $8(23.5 \%)$.

In the case of proton beam radiotherapy, usually twothirds (45 Gy) of the total dose was delivered via photon therapy and one-third (22 or $26 \mathrm{~Gy}$ ) of the dose consisted of proton irradiation; the mean total administered dose was 69 Gy (range 67-71 Gy) delivered as a 1.8-Gy dose per fraction. In the case of conventional fractionated photon irradiation, a dose ranging from 60 to $72 \mathrm{~Gy}$ delivered as a 2-Gy dose per fraction was administered by a modified linear accelerator system or by a helical tomotherapy device to the original tumor volume. For Gamma Knife treatments, the peripheral prescription dose ranged from 18 to 25 Gy (mean 22.25 Gy) with a prescription isodose of $50 \%$.

Seven patients (20.6\%) experienced complications directly related to radiation therapy, especially proton beam radiotherapy: 4 patients (11.8\%) experienced hypopituitarism; 2 (5.9\%) developed delayed temporal lobe radionecrosis, 1 of whom required surgical treatment for malignant edema; 2 patients (5.9\%) suffered from visual worsening; and 1 from hearing loss. One patient (2.9\%), who had undergone proton beam radiotherapy after surgery and GKRS for tumor recurrence, developed abducens nerve and lower cranial nerves impairment by the follow-up.

\section{Morbidity, Mortality, and Functional Status}

Table 2 lists patients' preoperative and postoperative neurological signs and cranial nerve function. Four cases (8.9\%) of cerebrospinal fluid leak were recorded; 3 of them were successfully treated by external lumbar drainage, and the remaining case required a lumbar peritoneal shunt. Other postoperative complications successfully treated by medical therapy were sinusitis in 2 cases (4.4\%), meningitis in 1 case $(2.2 \%)$, and severe hyponatremia in 1 case $(2.2 \%)$. One patient developed delayed hydrocephalus that was treated with a ventriculoperitoneal shunt. Mortality due to perioperative complications was recorded in 2 patients (4.4\%); the first patient died from a pulmonary embolism the day after surgery, and the second died from cerebellar hemorrhage 5 days after surgery. The mean preoperative KPS score was 89.78 (range 60-100), whereas the mean KPS score at the clinical evaluation 6 months after surgery was 92.81 (range 60-100). The mean best KPS score assessed at follow-up was 92.84 (range 60-100). The score improved in $26 \%$ of the patients, remained unchanged in $54 \%$, and worsened in $20 \%$.

\section{Analysis of $\mathrm{LOH}$}

The 1p36 LOH study was performed on 27 chordoma samples from patients who had undergone gross-total or subtotal resection and postoperative radiotherapy. Twentyone samples (77.8\%) showed LOH and $10(37.0 \%)$ of them displayed a wide region of $\mathrm{LOH}$ involving all the tested markers. The remaining 11 (40.7\%) samples displayed segmental LOH within the $1 \mathrm{p} 36$ region (Fig. 2). To determine whether LOH was confined to $1 \mathrm{p} 36$ or extended across $1 \mathrm{p}$, we tested further microsatellite markers (D1S2841, D1S1172, D1S2868, D1S2726, and D1S2696). Among the tumor samples exhibiting $\mathrm{LOH}$ at 1p36, 13 also exhibited $\mathrm{LOH}$ at a more centromeric location, suggesting a loss going beyond the $1 \mathrm{p} 36$ region, whereas 2 of them showed no allelic imbalance. We could exclude chromosome 1 monosomy in every tumor showing $1 \mathrm{p} 36 \mathrm{LOH}$. The remaining 6 specimens $(22.2 \%)$ displayed no $\mathrm{LOH}$ for any of the tested markers.

We grouped the patients according to $\mathrm{LOH}$ status at $1 \mathrm{p} 36$ and observed that all events (recurrence or death) clustered in the group with $1 \mathrm{p} 36 \mathrm{LOH}$. 
TABLE 2. Preoperative and postoperative neurological signs

\begin{tabular}{lccccc}
\hline & & \multicolumn{3}{c}{ Postop } \\
\cline { 3 - 6 } Deficit & Preop & Improved & Unchanged & Worsened & New Onset \\
\hline Hemiparesis & $6(13 \%)$ & $4 / 6$ & $2 / 6$ & 0 & 2 \\
\hline Cerebellar signs & $6(13 \%)$ & $3 / 6$ & $3 / 6$ & 0 & 0 \\
\hline Cranial nerve deficits & & & & \\
\hline I & $6(13 \%)$ & 0 & $6 / 1$ & 0 & 1 \\
\hline II & $12(27 \%)$ & $6 / 12$ & $6 / 12$ & 0 & 1 \\
\hline III & $10(22 \%)$ & $4 / 10$ & $6 / 10$ & 0 & 1 \\
\hline IV & $2(4 \%)$ & 0 & $2 / 2$ & 0 & 2 \\
\hline V & $6(13 \%)$ & $2 / 6$ & $4 / 6$ & 0 & 0 \\
\hline VI & $28(62 \%)$ & $10 / 28$ & $18 / 28$ & 0 & 1 \\
\hline VII & $8(18 \%)$ & $2 / 8$ & $6 / 8$ & 0 & 2 \\
\hline VIII & $2(4 \%)$ & 0 & $1 / 2$ & 0 & 1 \\
\hline IX-X-XI & $4(9 \%)$ & 0 & $4 / 4$ & 0 & 0 \\
\hline XII & $6(13 \%)$ & $3 / 6$ & $3 / 6$ & & 2 \\
\hline
\end{tabular}

\section{Disease Status and Patient Survival}

The average follow-up period calculated from the first treatment performed at our institution was 75.98 (range 1-240 months). Sixteen (35\%) patients died because of tumor progression, 2 (4.5\%) from perioperative complications, and $2(4.5 \%)$ from other causes. At the time of the last follow-up examination, 25 patients $(55.5 \%)$ were still alive; 19 patients (76\%) were alive and free of tumor or with stable tumor, whereas $6(24 \%)$ were alive with noticeable tumor progression.

Tumor relapse occurred in 18 patients $(40 \%)$, locally in 17 (94\%); in the remaining patient (6\%) spinal intradural seeding at the thoracic level was found. One patient experienced both local and spinal intradural tumor relapse. In 1 patient with advanced chordoma, liver and lung metastases were detected. Ten patients $(55.5 \%)$ underwent further treatment: surgery in 6 cases, GKRS in 2 cases, and molecular targeted therapy with imatinib mesylate in 2 patients not eligible for other therapies. The mean OS time after surgery was 75.98 months (range 1-240 months), whereas the mean overall PFS time was 64.98 months (range 5-240 months). The mean OS time after tumor relapse was 23.54 months (range 2-47 months). Kaplan-Meier analysis predicted OS rates of $77.4 \%, 66.8 \%, 61.2 \%$, and $56.9 \%$ at 3 , 5,7 , and 10 years, respectively, and PFS rates of $69.5 \%$, $58 \%, 48.1 \%$, and $44.4 \%$ (Fig. 3). In considering the variables tested as possible prognostic factors, 6 were found to be predictive of both OS and PFS on univariate analysis: age, rhinopharynx invasion, tumor removal, adjuvant therapy, preoperative KPS score, and LOH. In fitting the Cox proportional-hazards model for survival (whole model $\mathrm{p}=$ 0.0009 , Harrell's $C=0.7819), 3$ variables significantly affected survival (Table 3): rhinopharynx invasion (HR 4.26, 95\% CI 1.46-12.41, p = 0.008; Fig. 4A), radical or subtotal tumor removal (HR 0.30, 95\% CI 0.10-0.95, p = 0.041; Fig. 4B), and adjuvant therapy (HR 0. 35, 95\% CI 0.13$0.94, p=0.038$; Fig. $4 \mathrm{C}$ ). In fitting the Cox proportionalhazards model for PFS (whole model $\mathrm{p}<0.0001$, Harrell's $\mathrm{C}=0.8318), 3$ variables significantly affected survival: age (1-year HR 1.03, 95\% CI 1.005-1.06, $\mathrm{p}=0.022$; Fig. 4E), rhinopharynx invasion (HR 11.38, 95\% CI 3.82-33.91, $\mathrm{p}$ $<0.001$; Fig. 4D), and adjuvant therapy (HR 0.27, 95\% CI $0.09-0.78, \mathrm{p}=0.016$; Fig. 4F). Variables in both models revealed no interaction between them, and the proportionality of hazards was verified for each variable.

\section{Discussion}

Skull base chordomas are rare, locally aggressive, midline primary bone tumors arising from notochord remnants. ${ }^{1,11,17}$ Given the rarity of this disease, no standardized guidelines exist and thus most of our knowledge is based on anecdotal cases, case reports, and single-institution case series (class of evidence: Level 2 or 3). Moreover, some old series ${ }^{9,18,52}$ have included both SBCs and chondrosarcomas, even though it is known that low-grade chondro-

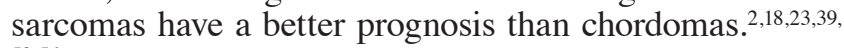
52,56

To the best of our knowledge, only 19 surgical series with at least 15 patients have been reported in the literature (Table 4). ${ }^{13}$ In the present study we considered a consecutive series of 45 patients treated at our institution in the period from 1990 to 2011 for a histological diagnosis of chordoma, completely fulfilling the pathological criteria described by Holton et al. ${ }^{21}$ Although a better long-term outcome in patients harboring chondroid chordoma has been reported,,$^{19,47,59}$ in our analysis the histological type did not influence prognosis. Since the 1990s, other authors have denied the prognostic significance of histological type. ${ }^{1-3,9,17,18,30,40}$ ${ }_{56,59}$ Hug and Slater even reported on the association between longer survival and the nonchondroid type. ${ }^{23}$

Skull base chordomas are generally considered to be slow-growing tumors, and the duration of follow-up is relevant in evaluating treatment results. Only 5 published series have reported a mean follow-up longer than 5 years (Table 4). ${ }^{17,44,52,56}$ In the present series the mean follow-up was longer than 6 years; in our opinion, the duration of follow-up is a crucial point in performing a critical review of the results of administered treatments. 


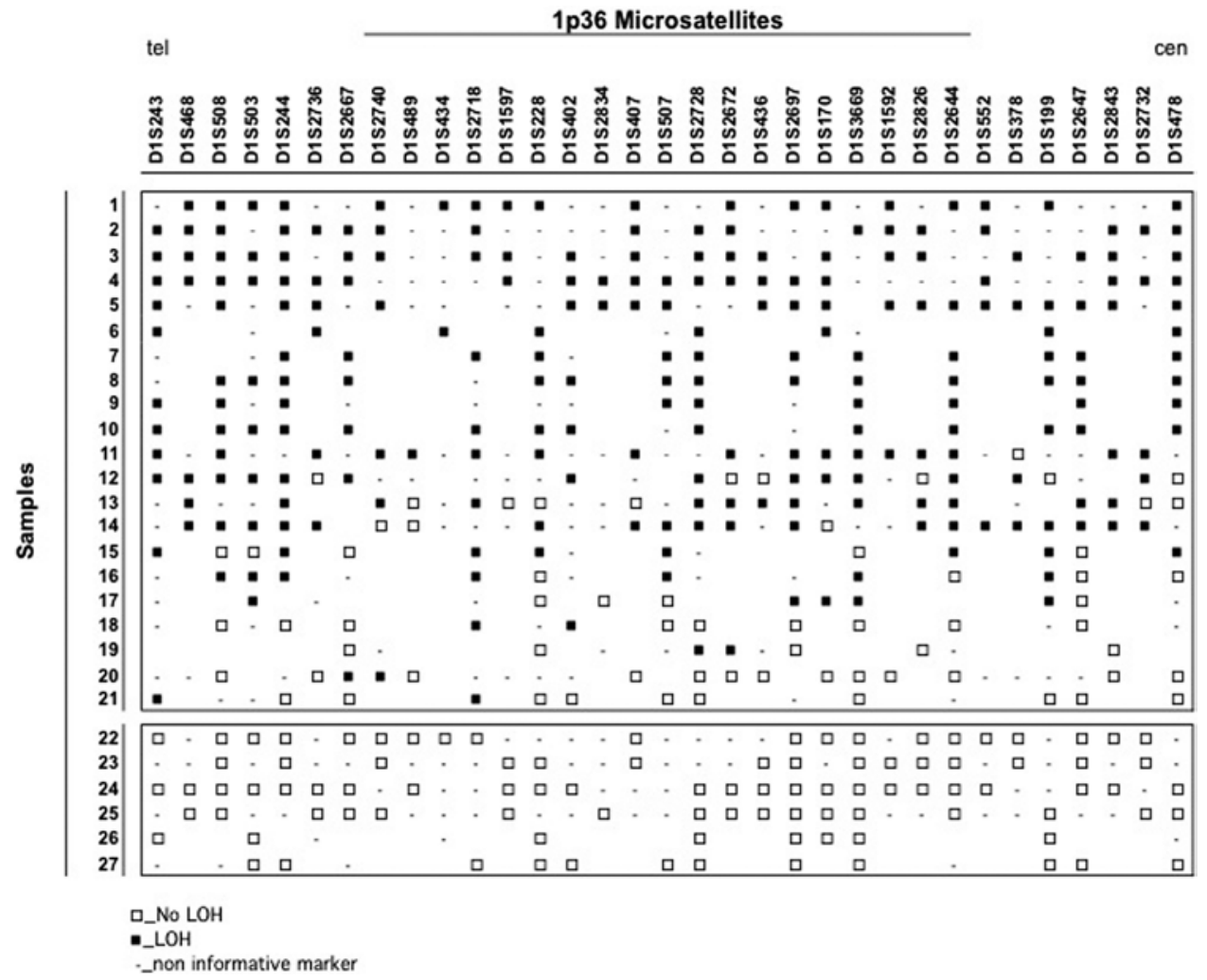

FIG. 2. 1 p36 LOH analysis of 27 chordoma samples (listed in rows) from 27 patients by using 33 microsatellite markers mapped to 1p36.33-1p36.12 (listed in columns from the most telomeric [tel] to the most centromeric [cen]). Black squares indicate LOH, white squares indicate retention of heterozygosity, and dashes indicate uninformative markers.

\section{Patient Population, Tumor Location, and Extension}

In our series epidemiological data are comparable to those reported in the literature (Table 4): we found a male predilection with a male/female ratio of $2: 1^{8,30,38}$ and an onset peak age of 46.7 years. ${ }^{1,8,10,11,18,19,49,53}$ Whether sex and age can affect prognosis is still a matter of debate. We did not find any significant correlation between patient sex and survival. Categorizing age according to its median, we found that patients younger than 48 years had significantly better OS $(p=0.011)$ and PFS $(0.016)$ on univariate analysis; however, in fitting the Cox proportional-hazards model, we found that age significantly affected only PFS $(\mathrm{p}=0.022)$.

Tumor extension into the cavernous sinus did not significantly impact survival, whereas rhinopharynx invasion ( $31 \%$ of cases) showed a strong correlation with a poorer outcome on multivariate analysis in terms of both OS (p $=0.008)$ and PFS $(\mathrm{p}<0.001)$, acting as an independent predictor of outcome; this represents a novel finding in the literature. Yasuda and colleagues observed that chor-
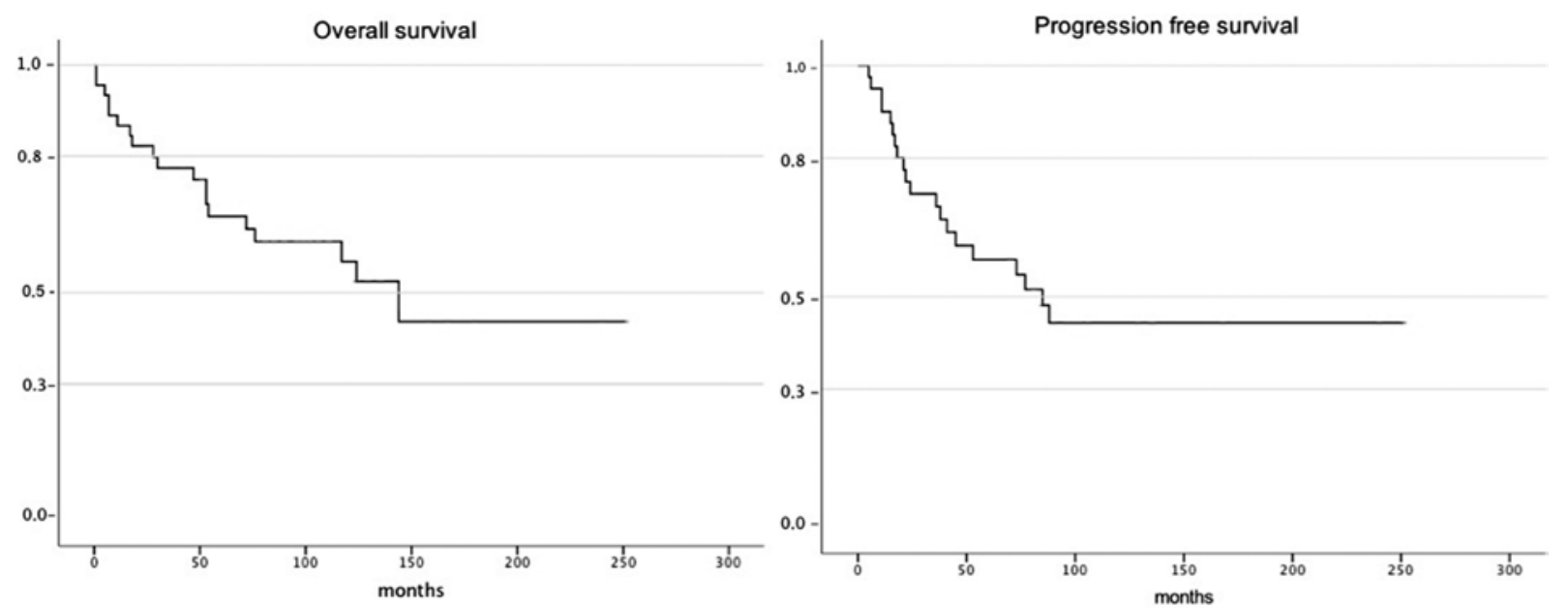

FIG. 3. Kaplan-Meier curves for OS (left) and PFS (right). 
TABLE 3. Summary of statistical results of multivariate analysis

\begin{tabular}{|c|c|c|}
\hline Variable & $\mathrm{OS}^{*}$ & PFS* \\
\hline Age (31-48 vs 49-61 yrs) & + & 0.022 \\
\hline Sex & - & - \\
\hline Rhinopharynx invasion (no vs yes) & 0.008 & $<0.001$ \\
\hline Tumor removal (radical/subtotal vs partial/biopsy) & 0.041 & + \\
\hline LOH (no vs yes) & + & + \\
\hline Adjuvant radiotherapy (no vs yes) & 0.038 & 0.016 \\
\hline Tumor histology (classic vs chondroid) & - & - \\
\hline Staged procedure (no vs yes) & - & - \\
\hline Previous surgery (no vs yes) & - & - \\
\hline Brainstem compression (no vs yes) & - & - \\
\hline Cavernous sinus invasion (no vs yes) & - & - \\
\hline Dural involvement (no vs yes) & - & - \\
\hline Preop KPS score (<80 vs $\geq 80)$ & + & + \\
\hline Sekhar classification $†$ & - & - \\
\hline Whole model $p$ value & 0.0009 & $<0.0001$ \\
\hline Harrell's C & 0.7819 & 0.8318 \\
\hline \multicolumn{3}{|c|}{$\begin{array}{l}-=\text { the variable's } p \text { value was }>0.20 \text { on univariate analysis, and therefore the } \\
\text { variable was not considered in the subsequent multivariate analysis; }+=\text { the } \\
\text { variable's } p \text { value was }<0.20 \text { on univariate analysis, but the variable did not } \\
\text { enter the multivariate model. } \\
\text { " Reported numbers are the } p \text { values for the single independent variables } \\
\text { entering the multivariate models, whose whole model } p \text { values are reported on } \\
\text { the bottom line. } \\
\dagger \text { Considered a categorical variable: comparisons among scores were con- } \\
\text { ducted using the lowest risk category of each scale as the reference category. }\end{array}$} \\
\hline
\end{tabular}

domas of the craniocervical junction (CCJ) have a poorer prognosis. ${ }^{59}$ According to their data, CCJ chordomas are more common in younger patients and, in contrast to our findings, a young age represents a negative prognostic factor; they argued that these 2 factors are probably related to each other. Nevertheless, rhinopharynx invasion is a very common finding in CCJ chordomas, and given our observations, we hypothesize that this invasion can explain the poorer prognosis. Rhinopharynx invasion adversely impacted prognosis because muscles represent a path of least resistance for tumor spreading. Moreover, infiltration of the pharyngobasilar fascia and rhinopharynx muscles often jeopardizes the possibility of obtaining total tumor resection and makes it extremely difficult to intraoperatively evaluate the true extent of resection.

The embryologic origin from clival bone marrow provides an explanation for the SBC's prevalent extradural location. ${ }^{56}$ In our series all tumors were primarily extradural, but most of the tumors secondarily invaded the intradural space (53\% of cases). In particular, in the $75 \%$ of patients who had undergone surgery prior to our referral, the tumor was growing through the dura, whereas only $45 \%$ of cases that had not been previously surgically treated presented with a transdural extension. These data, even if suggestive of a greater likelihood of dural transgression by tumor after a previous surgery, approach but do not reach statistical significance on the Pearson chi-squared test $(\mathrm{p}=0.079)$.

\section{Surgical Treatment}

Selection of the surgical approach was based on the size of the tumor and its anatomical location and extension. As previously stated, chordomas are primary extradural tumors, and since the dura is an important barrier against the tumor, an extradural route should be the primary approach,
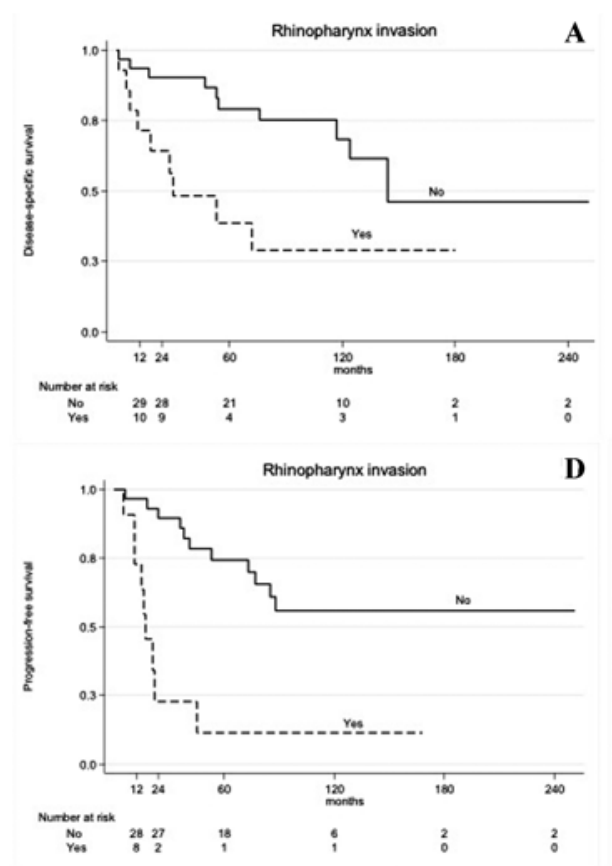
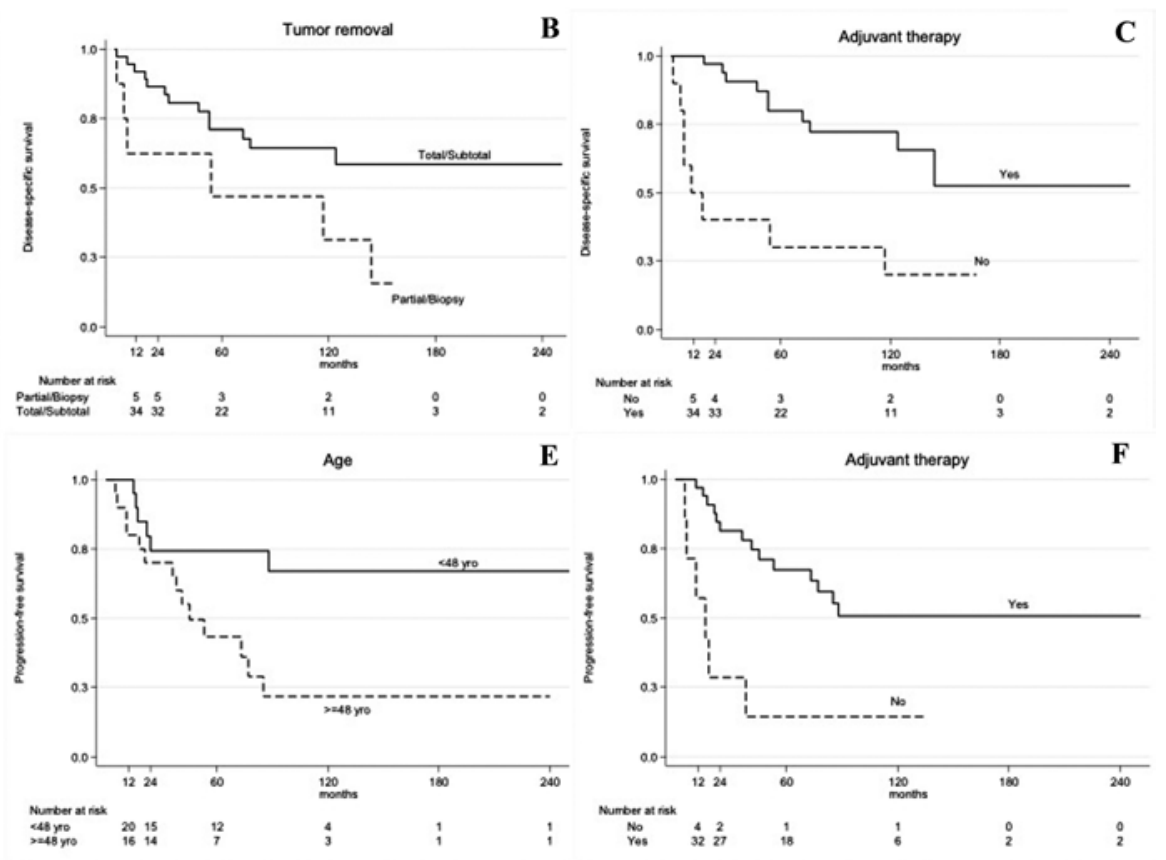

FIG. 4. Relevant Kaplan-Meier curves for clinical prognostic factors: OS according to rhinopharynx invasion (A); OS according to extent of tumor removal (B); OS according to adjuvant radiation therapy (C); PFS according to rhinopharynx invasion (D); PFS according to patient age (E); and PFS according to adjuvant radiation therapy (F). yro = years old. 
TABLE 4. Literature review of SBC series with at least 15 patients

\begin{tabular}{|c|c|c|c|c|c|c|c|c|c|c|c|c|c|}
\hline \multirow[b]{2}{*}{ Authors \& Year } & \multirow{2}{*}{$\begin{array}{c}\text { No. of } \\
\text { Patients }\end{array}$} & \multirow{2}{*}{$\begin{array}{c}\text { Mean Age } \\
\quad(y r s)\end{array}$} & \multirow{2}{*}{$\begin{array}{c}\text { FU } \\
\text { (mos) }\end{array}$} & \multicolumn{2}{|c|}{ Approaches (\%) } & \multicolumn{2}{|c|}{ Resection (\%) } & \multirow{2}{*}{$\begin{array}{c}\text { Mortality } \\
(\%)\end{array}$} & \multirow[b]{2}{*}{ RT (\%) } & \multicolumn{2}{|c|}{ OS $(\%)$} & \multicolumn{2}{|c|}{ PFS (\%) } \\
\hline & & & & Ant & Lat & $\mathrm{ST} / \mathrm{P}$ & GT & & & 5 Yrs & $10 \mathrm{Yrs}$ & 5 Yrs & $10 \mathrm{Yrs}$ \\
\hline Forsyth et al., 1993 & 51 & 42.6 & 99 & NR & NR & 74 & 0 & NR & 76 & 51 & 35 & 23.0 & 23.0 \\
\hline Gay et al., 1995 & 46 & 45.1 & 45 & 27 & 70 & NR & NR & 5 & NR & NR & NR & 65.0 & 65.0 \\
\hline al-Mefty \& Borba, 1997 & 25 & 38.4 & 25.4 & 50 & 40 & 48 & 43 & 4 & 76 & NR & NR & NR & NR \\
\hline Tamaki et al., 2001 & 17 & 47 & 58.8 & 47 & 35.2 & 70.6 & 29.4 & NR & 76 & 64 & NR & 51 & NR \\
\hline Crockard et al., 2001 & $42^{*}$ & 58.1 & 51 & 85 & 11 & 22 & 72 & 4.3 & 62 & 77 & 69 & NR & NR \\
\hline Sekhar et al., 2001 & 42 & NR & NR & NR & NR & 28 & 59 & 12 & NR & NR & NR & NR & NR \\
\hline Colli \& Al-Mefty, $2001^{10}$ & 53 & 40.7 & 49.9 & 40 & 52 & 28 & 45 & 7 & 68 & 50 & 24 & 51.0 & NR \\
\hline Sen \& Triana, 2001 & 29 & 39.0 & 20.5 & NR & NR & 38 & 62 & 3 & 20 & NR & NR & NR & NR \\
\hline Pallini et al., 2003 & 26 & 50.3 & 65.7 & 60 & 14 & 27 & 42 & 0 & 31 & NR & NR & NR & NR \\
\hline Pamir et al., 2004 & 26 & 40.5 & 48.5 & 42 & 58 & 41 & 12 & 4 & 27 & NR & NR & NR & NR \\
\hline Tzortzidis et al., 2006 & 74 & NR & 96 & 15 & 78 & 28.4 & 72 & 3 & 35 & NR & NR & 41.0 & 31.0 \\
\hline Samii et al., 2007 & 49 & 39.1 & 63 & 30 & 46 & 50.6 & 49.4 & $2 / 5.3 \dagger$ & 39 & 65 & 39 & NR & NR \\
\hline Almefty et al., 2007 & 89 & 38.3 & 48 & NR & NR & 55 & 45 & NR & 75 & $74 \ddagger$ & $59 \ddagger$ & $51.4 \ddagger$ & $25 \ddagger$ \\
\hline Cho et al., 2008 & 19 & 37.3 & 56 & 48 & 52 & 44 & 12 & NR & NR & 84.6 & 80 & 40.0 & NR \\
\hline Takahashi et al., 2009 & 32 & 41.4 & 36.3 & 45.8 & 49 & 100 & 0 & 0 & 28.1 & 92.5 & NR & 29.3 & NR \\
\hline Sen et al., 2010 & $65 \S$ & 40.7 & 66 & 32.3 & 46.2 & NRT & 58.5 & NR & 67.7 & 75 & NR & NR & NR \\
\hline Yasuda et al., 2012 & $40^{* *}$ & 45.1 & 46.1 & 88 & 12 & 65 & 30 & 0 & NR & 83.4 & NR & 90.0 & NR \\
\hline Di Maio et al., 2012 & 95 & 42.6 & 38.3 & 47.4 & 42.1 & 29.5 & 70.5 & 3.2 & 42.9 & 74 & NR & 56 & NR \\
\hline Chibbaro et al., 2014 & 54 & 49 & 34 & 100 & 0 & 35 & 65 & 1.8 & 100 & NR & NR & NR & NR \\
\hline Mean†† & 46 & 43.2 & 52.6 & 50.5 & 40.4 & 46.1 & 42.6 & 3.5 & 54.9 & 71.9 & 51 & 49.8 & 36 \\
\hline Present series & 45 & 46.7 & 76 & 75.5 & 21 & 40 & 42 & 4.4 & 77 & 66.8 & 56.9 & 69.5 & 44.4 \\
\hline
\end{tabular}

Ant = anterior; $\mathrm{GT}$ = gross total; $\mathrm{NR}=$ not reported; $\mathrm{P}=$ partial; $\mathrm{RT}$ = radiotherapy; $\mathrm{ST}$ = subtotal.

* Thirty-two clival, 10 CCJ.

$\dagger$ Second surgery.

‡ Excluding chondroid chordomas.

$\S$ Forty-five clival, 20 CCJ.

I $41.5 \%$ "incomplete" resection.

** Seventeen clival, 13 CCJ, 10 cervical spine.

†† Mean values do not include the present series.

unless the dura is invaded by tumor. According to Sen and colleagues' philosophy, ${ }^{52}$ lateral skull base approaches are preferred for tumors surrounding the internal carotid artery, intimately involving the cavernous sinus, the temporal bone, the vertebrobasilar arteries, and the brainstem, because lateral routes allowed for better surgical control of neurovascular structures, an easier intraoperative repair of dural openings, and a better separation of the brainstemtumor interface. Midline anterior approaches provided access to the clivus, taking advantage of an anatomical path of dissection free of major neurovascular structures and reducing parenchymal injury and intradural cranial nerve damage. ${ }^{4}$

Lateral and anterolateral approaches were preferentially used in the first years of our experience, but they have been progressively replaced by the extensive application of anterior approaches and endoscopic procedures. According to the main published series, the choice of surgical route is extremely variable, depending mostly on the surgeon's confidence with particular approaches: use of the anterior approach varies from $15 \%$ in the Tzortzidis series to $85 \%$ in the Crockard series and up to $100 \%$ in the purely endoscopic series published by Chibbaro et al. ${ }^{7,11,56}$ In contrast, the use of lateral approaches ranged from 0 to $78 \%$. $^{7,11,56}$
In the present series, gross-total resection was achieved in $42 \%$ of cases; this finding is close to the mean value reported in the literature (mean $42.6 \%$, range $0-72 \%)^{7,11,17}$ Extensive tumor resection seemed to be easier to achieve in patients who had not undergone previous resection, as mentioned in other reports, ${ }^{52}$ although in our series this observation did not reach statistical significance. On multivariate analysis our data confirmed a statistically significant correlation between the degree of tumor resection and survival $(\mathrm{p}=0.041)$, as was shown in the meta-analysis published by Di Maio in 2011. ${ }^{13}$

\section{Morbidity, Mortality, and Functional Outcome}

We, like other authors, found that postoperative functional status was strongly influenced by disease progression and cranial nerve impairment. ${ }^{10,14,18}$ In the cited series the postoperative onset of new cranial nerve palsies ranges from $33 \%$ to $80 \% .^{18,50}$ Major neurological morbidity in the present study was limited to only 2 cases (4.4\%) of hemiparesis, and 1 of these partially recovered at follow-up. Surgical mortality $(4.4 \%)$ was comparable to data reported in the literature (0-12\%; Table 4$){ }^{44,50}$

The mean preoperative KPS scores reported in the literature on patients harboring SBCs ranges from 80 to 
$87 .{ }^{18,45,50,52,56}$ In our series the mean preoperative score was 89.78. Univariate analysis of survival showed that patients presenting with a preoperative KPS score $\geq 80$ had a statistically significant longer OS and PFS than patients with worse preoperative general conditions $(\mathrm{p}=0.012$ and 0.044); however, these data were not statistically significant on fitting the Cox proportional-hazards model.

The mean postoperative KPS score as reported by major published series ranges from 78 to $86,{ }^{18,45,50,51,56}$ with a rate of fully active patients ranging from $67 \%$ to $76 \% .^{8,18}$ In our series the mean best postoperative KPS score recorded at follow-up was 92.84 (range 60-100), higher than the score recorded before surgery. These data suggest that the overall impact of surgery on patient quality of life seems to be positive or at least not detrimental.

\section{Radiation Therapies}

High-dose radiotherapy plays an important role in the management of chordomas, providing better tumor control. 3,6,23 The most common delivery methods include fractionated radiotherapy, charged-particle radiation therapy with proton beams or carbon ions, and radiosurgery using Gamma Knife and Cyber Knife. ${ }^{3,30,31,38,40,46,54,56}$ Criteria for the application of radiotherapy as adjuvant treatment in the multimodal management of SBCs are still a matter of debate. Clinical series have reported the percentage of patients undergoing radiotherapy as ranging from $20 \%$ to $100 \%$ (Table 4). ${ }^{3,6,23}$ There are 2 main treatment philosophies: resection followed by radiotherapy only in patients who have tumor remnants, ${ }^{11,56}$ or radiotherapy administered proactively, regardless of the presence of residual tumor., ${ }^{1,56}$ Since 2001 we have routinely delivered adjuvant radiation therapies to the tumor bed even in cases of gross-total resection. Considering the high risk of microscopic infiltration of the resection margins by tumor cells, we reasoned that our strategy would result in better PFS. However, statistical significance was not found in comparing the survival of patients with gross-total resection who were treated with adjuvant radiation therapy versus those who were not. Even in the literature, studies aimed at investigating this topic are still lacking. In the present series, $75.5 \%$ of patients were treated with different types of radiation therapy. On multivariate analysis, we found that radiotherapy positively affected both OS $(\mathrm{p}=0.038)$ and PFS $(p=0.016)$. No significant data were found when separately considering patients who underwent different types of radiotherapy. In the literature, we still lack clinical series comparing the efficacy and safety of different types of radiation therapies for SBCs.

\section{Biological Prognostic Factors}

Previous studies have investigated the classic pathological paradigms in relation to the biological and clinical behavior of SBCs. ${ }^{10,11,18,40}$ The proliferative ability of SBCs appears to be closely associated with recurrence and nuclear pleomorphism ${ }^{32}$ and correlates with the combination of p53 overexpression, anaplasty, high-grade atypia, and diffuse proliferation. ${ }^{33}$ Expression of telomerase transcriptase mRNA and the mutation of p53 may indicate cases at risk for early recurrence, ${ }^{44}$ while the expression of MIB-1, p53, and cyclin D1 was identified as a possible predictor of recurrence. ${ }^{28}$ Tumor doubling time correlated with age, sex, histological parameters, and $\mathrm{Ki} 67$ labeling index. ${ }^{21}$

Nevertheless, today we know very little about the oncogenesis of chordomas, although it is well established that not all chordomas behave the same. There are at least 2 subsets of SBCs with distinct clinical behavior: one group with a benign course and another with an aggressive and rapidly progressive course. Chordomas are polyclonal tumors ${ }^{40}$ with diverse chromosomal aberrations. An abnormal karyotype has been found in about half of chordomas, with chromosomal deletions being more frequent than amplifications. ${ }^{32,33}$ Chordomas have 3 genetic lesions that have potential clinical and therapeutic importance: $1 \mathrm{p} 36$ loss, ${ }^{41,42}$ 9p21 loss, ${ }^{32}$ and 7q gain. ${ }^{30,33,43}$ Failure of apoptosis is known to be a key mechanism for the induction and maintenance of the neoplastic phenotype. Apoptotic mechanisms are involved in notochord formation, and apoptosis is deregulated in chordoma. ${ }^{16}$ Loss of heterozygosity in the 1 p36 region has been indicated as a possible negative prognostic factor by Longoni et al. ${ }^{27}$ In 27 chordoma samples from the 45 patients described above, we investigated the LOH in $1 \mathrm{p} 36$. Stratifying patients according to $\mathrm{LOH}$ status at $1 \mathrm{p} 36$ on survival analysis, we observed that all events (recurrence or death) clustered in the group of patients with $1 \mathrm{p} 36 \mathrm{LOH}$. Nevertheless, this biological marker did not reach statistical significance on multivariate analysis. Even though 1p36 $\mathrm{LOH}$ was not an independent predictor of outcome, genetic analysis should be performed in larger series of patients to point to new markers possibly predicting a different recurrence rate. Ideally, the aggressiveness of surgery and the indication and timing of adjuvant radiation therapy should be settled based on both patient characteristics and tumor biology.

\section{Status of the Disease and Survival}

Compared with those in previous major clinical reports (mean follow-up 52.6 months), ${ }^{8,10,11,17,49,58}$ the follow-up in our series (average 75.98 months) was the longest after that reported by Forsyth et al. (99 months). ${ }^{17}$ At the last followup examination, $35 \%$ of our patients had died of tumor progression or complications from it. Average OS was 75.98 months, and the predicted 5- and 10-year OS were $66.8 \%$ and $56.9 \%$, respectively; predicted PFS at 5 and 10 years were $58 \%$ and $44.4 \%$, respectively. These data are comparable to those previously reported (Table 4).

\section{Conclusions}

Skull base chordomas are extremely rare tumors that are challenging to treat. No standardized guidelines exist, and clinical series are usually not large and homogeneous enough to perform a robust statistical analysis. Resection remains the treatment of choice for primary and recurrent SBCs.

Multivariate analysis showed that the extent of resection, adjuvant radiation therapy, and the absence of rhinopharynx invasion were positive independent predictors of $\mathrm{OS}$, whereas the 2 last variables and a younger patient age were positive independent predictors of PFS.

Genetic analysis, while showing interesting results, failed to define $1 \mathrm{p} 36 \mathrm{LOH}$ as an independent predictor of 
clinical outcome. Additional studies in a greater number of patients should be performed to point to new markers possibly predicting a different recurrence rate in an attempt to define tailored treatments according to a patient's tumor biology.

\section{Acknowledgments}

Genetic analysis (performed by L.F. and P.R.) was supported by Associazione Italiana per la Ricerca sul Cancro, the Italian Association for Cancer Research.

\section{References}

1. al-Mefty O, Borba LA: Skull base chordomas: a management challenge. J Neurosurg 86:182-189, 1997

2. Almefty K, Pravdenkova S, Colli BO, Al-Mefty O, Gokden M: Chordoma and chondrosarcoma: similar, but quite different, skull base tumors. Cancer 110:2457-2467, 2007

3. Austin JP, Urie MM, Cardenosa G, Munzenrider JE: Probable causes of recurrence in patients with chordoma and chondrosarcoma of the base of skull and cervical spine. Int J Radiat Oncol Biol Phys 25:439-444, 1993

4. Boari N, Roberti F, Biglioli F, Caputy AJ, Mortini P: Quantification of clival and paraclival exposure in the Le Fort I transmaxillary transpterygoid approach: a microanatomical study. J Neurosurg 113:1011-1018, 2010

5. Carpentier A, Polivka M, Blanquet A, Lot G, George B: Suboccipital and cervical chordomas: the value of aggressive treatment at first presentation of the disease. J Neurosurg 97:1070-1077, 2002

6. Castro JR, Linstadt DE, Bahary JP, Petti PL, Daftari I, Collier JM, et al: Experience in charged particle irradiation of tumors of the skull base: 1977-1992. Int J Radiat Oncol Biol Phys 29:647-655, 1994

7. Chibbaro S, Cornelius JF, Froelich S, Tigan L, Kehrli P, Debry C, et al: Endoscopic endonasal approach in the management of skull base chordomas - clinical experience on a large series, technique, outcome, and pitfalls. Neurosurg Rev 37:217-225, 2014

8. Cho YH, Kim JH, Khang SK, Lee JK, Kim CJ: Chordomas and chondrosarcomas of the skull base: comparative analysis of clinical results in 30 patients. Neurosurg Rev 31:35-43, 2008

9. Colli B, Al-Mefty O: Chordomas of the craniocervical junction: follow-up review and prognostic factors. J Neurosurg 95:933-943, 2001

10. Colli BO, Al-Mefty O: Chordomas of the skull base: followup review and prognostic factors. Neurosurg Focus 10(3):E1, 2001

11. Crockard HA, Steel T, Plowman N, Singh A, Crossman J, Revesz T, et al: A multidisciplinary team approach to skull base chordomas. J Neurosurg 95:175-183, 2001

12. Di Maio S, Rostomily R, Sekhar LN: Current surgical outcomes for cranial base chordomas: cohort study of 95 patients. Neurosurgery 70:1355-1360, 2012

13. Di Maio S, Temkin N, Ramanathan D, Sekhar LN: Current comprehensive management of cranial base chordomas: 10year meta-analysis of observational studies. J Neurosurg 115:1094-1105, 2011

14. Diaz RJ, Maggacis N, Zhang S, Cusimano MD: Determinants of quality of life in patients with skull base chordoma. J Neurosurg 120:528-537, 2014

15. Eriksson B, Gunterberg B, Kindblom LG: Chordoma. A clinicopathologic and prognostic study of a Swedish national series. Acta Orthop Scand 52:49-58, 1981

16. Ferrari L, Pistocchi A, Libera L, Boari N, Mortini P, Bellipanni G, et al: FAS/FASL are dysregulated in chordoma and their loss-of-function impairs zebrafish notochord formation. Oncotarget 5:5712-5724, 2014
17. Forsyth PA, Cascino TL, Shaw EG, Scheithauer BW, O'Fallon JR, Dozier JC, et al: Intracranial chordomas: a clinicopathological and prognostic study of 51 cases. J Neurosurg 78:741-747, 1993

18. Gay E, Sekhar LN, Rubinstein E, Wright DC, Sen C, Janecka IP, et al: Chordomas and chondrosarcomas of the cranial base: results and follow-up of 60 patients. Neurosurgery 36:887-897, 1995

19. Heffelfinger MJ, Dahlin DC, MacCarty CS, Beabout JW: Chordomas and cartilaginous tumors at the skull base. Cancer 32:410-420, 1973

20. Higinbotham NL, Phillips RF, Farr HW, Hustu HO: Chordoma. Thirty-five-year study at Memorial Hospital. Cancer 20:1841-1850, 1967

21. Holton JL, Steel T, Luxsuwong M, Crockard HA, Revesz T: Skull base chordomas: correlation of tumour doubling time with age, mitosis and Ki67 proliferation index. Neuropathol Appl Neurobiol 26:497-503, 2000

22. Hug EB, Fitzek MM, Liebsch NJ, Munzenrider JE: Locally challenging osteo- and chondrogenic tumors of the axial skeleton: results of combined proton and photon radiation therapy using three-dimensional treatment planning. Int J Radiat Oncol Biol Phys 31:467-476, 1995

23. Hug EB, Slater JD: Proton radiation therapy for chordomas and chondrosarcomas of the skull base. Neurosurg Clin $\mathbf{N}$ Am 11:627-638, 2000

24. Kamrin RP, Potanos JN, Pool JL: An evaluation of the diagnosis and treatment of chordoma. J Neurol Neurosurg Psychiatry 27:157-165, 1964

25. Lanzino G, Dumont AS, Lopes MB, Laws ER Jr: Skull base chordomas: overview of disease, management options, and outcome. Neurosurg Focus 10(3):E12, 2001

26. Larizza L, Mortini P, Riva P: Update on the cytogenetics and molecular genetics of chordoma. Hered Cancer Clin Pract 3:29-41, 2005

27. Longoni M, Orzan F, Stroppi M, Boari N, Mortini P, Riva P: Evaluation of 1p36 markers and clinical outcome in a skull base chordoma study. Neuro Oncol 10:52-60, 2008

28. Matsuno A, Sasaki T, Nagashima T, Matsuura R, Tanaka $\mathrm{H}$, Hirakawa M, et al: Immunohistochemical examination of proliferative potentials and the expression of cell cyclerelated proteins of intracranial chordomas. Hum Pathol 28:714-719, 1997

29. Miozzo M, Dalprà L, Riva P, Volontà M, Macciardi F, Pericotti S, et al: A tumor suppressor locus in familial and sporadic chordoma maps to 1p36. Int J Cancer 87:68-72, 2000

30. Munzenrider JE, Liebsch NJ: Proton therapy for tumors of the skull base. Strahlenther Onkol 175 (Suppl 2):57-63, 1999

31. Muthukumar N, Kondziolka D, Lunsford LD, Flickinger JC: Stereotactic radiosurgery for chordoma and chondrosarcoma: further experiences. Int J Radiat Oncol Biol Phys 41:387392,1998

32. Naka T, Boltze C, Samii A, Herold C, Ostertag H, Iwamoto Y, et al: Skull base and nonskull base chordomas: clinicopathologic and immunohistochemical study with special reference to nuclear pleomorphism and proliferative ability. Cancer 98:1934-1941, 2003

33. Naka T, Fukuda T, Chuman H, Iwamoto Y, Sugioka Y, Fukui M, et al: Proliferative activities in conventional chordoma: a clinicopathologic, DNA flow cytometric, and immunohistochemical analysis of 17 specimens with special reference to anaplastic chordoma showing a diffuse proliferation and nuclear atypia. Hum Pathol 27:381-388, 1996

34. Naka T, Iwamoto Y, Shinohara N, Chuman H, Fukui M, Tsuneyoshi M: Cytokeratin subtyping in chordomas and the fetal notochord: an immunohistochemical analysis of aberrant expression. Mod Pathol 10:545-551, 1997

35. Naka T, Oda Y, Iwamoto Y, Shinohara N, Chuman H, Fu- 
kui M, et al: Immunohistochemical analysis of E-cadherin, alpha-catenin, beta-catenin, gamma-catenin, and neural cell adhesion molecule (NCAM) in chordoma. J Clin Pathol 54:945-950, 2001

36. Nishigaya K, Kaneko M, Ohashi Y, Nukui H: Intradural retroclival chordoma without bone involvement: no tumor regrowth 5 years after operation. Case report. J Neurosurg 88:764-768, 1998

37. Nishimura T, Nishida N, Itoh T, Kuno M, Minata M, Komeda $\mathrm{T}$, et al: Comprehensive allelotyping of well-differentiated human hepatocellular carcinoma with semiquantitative determination of chromosomal gain or loss. Genes Chromosomes Cancer 35:329-339, 2002

38. Noël G, Feuvret L, Dhermain F, Mammar H, Haie-Méder C, Ponvert D, et al: [Chordomas of the base of the skull and upper cervical spine. 100 patients irradiated by a 3D conformal technique combining photon and proton beams.] Cancer Radiother 9:161-174, 2005 (Fr)

39. Noël G, Habrand JL, Jauffret E, de Crevoisier R, Dederke S, Mammar H, et al: Radiation therapy for chordoma and chondrosarcoma of the skull base and the cervical spine. Prognostic factors and patterns of failure. Strahlenther Onkol 179:241-248, 2003

40. O'Connell JX, Renard LG, Liebsch NJ, Efird JT, Munzenrider JE, Rosenberg AE: Base of skull chordoma. A correlative study of histologic and clinical features of 62 cases. Cancer 74:2261-2267, 1994

41. O'Hara BJ, Paetau A, Miettinen M: Keratin subsets and monoclonal antibody HBME-1 in chordoma: immunohistochemical differential diagnosis between tumors simulating chordoma. Hum Pathol 29:119-126, 1998

42. Orzan F, Terreni MR, Longoni M, Boari N, Mortini P, Doglioni C, et al: Expression study of the target receptor tyrosine kinase of Imatinib mesylate in skull base chordomas. Oncol Rep 18:249-252, 2007

43. Paavolainen P, Teppo L: Chordoma in Finland. Acta Orthop Scand 47:46-51, 1976

44. Pallini R, Maira G, Pierconti F, Falchetti ML, Alvino E, Cimino-Reale G, et al: Chordoma of the skull base: predictors of tumor recurrence. J Neurosurg 98:812-822, 2003

45. Pamir MN, Kilic T, Ture U, Ozek MM: Multimodality management of 26 skull-base chordomas with 4-year mean follow-up: experience at a single institution. Acta Neurochir (Wien) 146:343-354, 2004

46. Pearlman AW, Friedman M: Radical radiation therapy of chordoma. Am J Roentgenol Radium Ther Nucl Med 108:332-341, 1970

47. Raffel C, Wright DC, Gutin PH, Wilson CB: Cranial chordomas: clinical presentation and results of operative and radiation therapy in twenty-six patients. Neurosurgery 17:703-710, 1985

48. Riva P, Crosti F, Orzan F, Dalprà L, Mortini P, Parafioriti A, et al: Mapping of candidate region for chordoma development to $1 \mathrm{p} 36.13$ by $\mathrm{LOH}$ analysis. Int J Cancer 107:493-497, 2003

49. Samii A, Gerganov VM, Herold C, Hayashi N, Naka T, Mirzayan MJ, et al: Chordomas of the skull base: surgical management and outcome. J Neurosurg 107:319-324, 2007
50. Sekhar LN, Pranatartiharan R, Chanda A, Wright DC: Chordomas and chondrosarcomas of the skull base: results and complications of surgical management. Neurosurg Focus 10(3):E2, 2001

51. Sen C, Triana A: Cranial chordomas: results of radical excision. Neurosurg Focus 10(3):E3, 2001

52. Sen C, Triana AI, Berglind N, Godbold J, Shrivastava RK: Clival chordomas: clinical management, results, and complications in 71 patients. J Neurosurg 113:1059-1071, 2010

53. Stüer C, Schramm J, Schaller C: Skull base chordomas: management and results. Neurol Med Chir (Tokyo) 46:118-125, 2006

54. Takahashi S, Kawase T, Yoshida K, Hasegawa A, Mizoe JE: Skull base chordomas: efficacy of surgery followed by carbon ion radiotherapy. Acta Neurochir (Wien) 151:759-769, 2009

55. Tamaki N, Nagashima T, Ehara K, Motooka Y, Barua KK: Surgical approaches and strategies for skull base chordomas. Neurosurg Focus 10(3):E9, 2001

56. Tzortzidis F, Elahi F, Wright D, Natarajan SK, Sekhar LN: Patient outcome at long-term follow-up after aggressive microsurgical resection of cranial base chordomas. Neurosurgery 59:230-237, 2006

57. Volpe NJ, Liebsch NJ, Munzenrider JE, Lessell S: Neuroophthalmologic findings in chordoma and chondrosarcoma of the skull base. Am J Ophthalmol 115:97-104, 1993

58. Watkins L, Khudados ES, Kaleoglu M, Revesz T, Sacares P, Crockard HA: Skull base chordomas: a review of 38 patients, 1958-88. Br J Neurosurg 7:241-248, 1993

59. Yasuda M, Bresson D, Chibbaro S, Cornelius JF, Polivka M, Feuvret L, et al: Chordomas of the skull base and cervical spine: clinical outcomes associated with a multimodal surgical resection combined with proton-beam radiation in 40 patients. Neurosurg Rev 35:171-183, 2012

\section{Disclosures}

The authors report no conflict of interest concerning the materials or methods used in this study or the findings specified in this paper.

\section{Author Contributions}

Conception and design: Boari, Mortini. Acquisition of data: Boari, Gagliardi, Cavalli, Ferrari. Analysis and interpretation of data: Boari, Gagliardi, Gemma, Mortini. Drafting the article: Boari, Gagliardi, Ferrari. Critically revising the article: Boari, Riva, Mortini. Reviewed submitted version of manuscript: Boari, Cavalli, Riva, Mortini. Approved the final version of the manuscript on behalf of all authors: Boari. Statistical analysis: Cavalli, Gemma. Administrative/technical/material support: Riva, Mortini. Study supervision: Boari, Mortini. Genetic analysis: Ferrari, Riva.

\section{Correspondence}

Nicola Boari, Unit of Neurosurgery and Gamma Knife Radiosurgery, I.R.C.C.S. San Raffaele Hospital, Via Olgettina 60, Milano 20132, Italy. email: boari.nicola@hsr.it. 